\title{
Research on the New Enterprise Staff Performance Management Methodology based on the Performance Management Process Model
}

\author{
Fangjing $\mathrm{Li}^{1}$ \\ ${ }^{1}$ Xi'an International University, \\ Xi'an 710077,China
}

\begin{abstract}
In this paper, we conduct research on the new enterprise staff performance management methodology based on the management process model. Performance management has become an important management function which is the enterprise to realize strategic target of the important means and ways. How to establish a scientific and standardized performance management system which has become a problem paid attention to by companies. Our method combines the process model with the traditional management approach which enhances the overall performance. In the future, we will conduct more corresponding research to optimize the current method.
\end{abstract}

Keywords: Enterprise Staff; Performance Management; Management Process Model.

\section{Introduction}

Performance management is the job of the managers ensures that employees and its output can be consistent with the goal of enterprise process, is a central part of the win competitive advantage. Performance management is goal oriented. Managers and employees in target, mission requirements, as well as the direction, on the basis of consensus, form a community of interests and responsibilities. Jointly develop and promote the enterprises and individuals to create high performance successfully realize the goal of enterprise process. Performance management has become an important management function, is the enterprise to realize strategic target of the important means and ways. How to establish a scientific and standardized performance management system which has become a problem paid attention to by companies. In the process of establishing and perfecting performance management system, some business is very successful, but the development of different enterprises, enterprise culture and the enterprise organizational structure is different. Therefore, enterprises must establish performance management system is suitable for their own organization. And establish a performance management system is a process step by step, gradually perfect and therefore, the enterprise to set up a scientific and effective performance management system, the performance management system is essential to a more comprehensive understanding.

Study of the theory of employee performance management system for the enterprise usually has four basic starting point based on ability, based on the results of research, based on the behavior and strategy. In the formation of several research ideas enterprise employee performance management system has been widely used. Based on the ability of the performance management system, the main assessment staff knowledge and ability is to get the job done. Based on the results of performance management system issued by the organization's goal is very clear case is valid. Performance management is largely based on behavior by observing the staff at the completion of work to complete the related process of role behavior. The performance management system based on the strategic emphasis on enterprise strategy target layers of decomposition, the staff's daily work always points to the enterprise strategic target realization. Therefore, we believe that the competitiveness of enterprises general results and performance management for the enterprise 
internal core elements of common concern, enterprise competitiveness theory research should provide a foundation for the enterprise. Essence industry employee performance management is a win-win strategy, between the enterprise and the staff individual enterprises according to company strategy development target decomposition to different jobs, closely related to the general employee performance and development of the enterprise. But the current actual situation it is difficult to have the staff of state-owned enterprises can do the goal of performance management and enterprise development together. In our country enterprise, in many cases, the solution of the management work is using administrative manner and there are very few in this performance management way to solve [1-2].
To deal with the mentioned challenges, in this paper, we conduct in-depth research on the new enterprise staff performance management methodology based on the management process model. Performance management in enterprise management is the core control function. It is the enterprise to realize the strategic target of effective control. Performance management ideas and methods are being used by many companies in the world, has been more and more important for Chinese entrepreneurs. Performance management will be the country's enterprises developing international competitiveness of the most important management system. In the following sections, we will introduce our proposed methodology and approaches in detail. In the figure one, we show the basic pattern of the research.

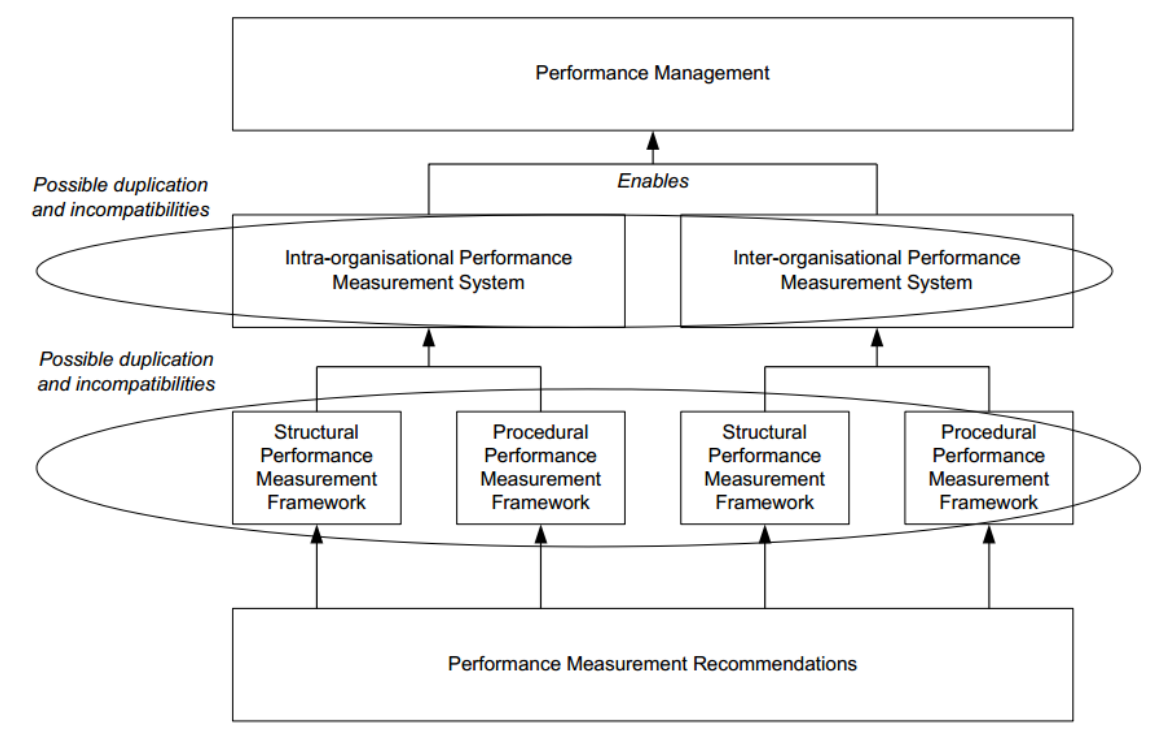

Figure 1. The Flowchart of the Enterprise Staff Performance Management Methodology

\section{Our Proposed Methodology}

\section{The Traditional Staff Performance} Management. Performance Management is the individual or group to achieve goals in the process of effective behavior as well as the realization of effective work, its behavior and work performance and its contribution to the enterprise. Enterprise performance management is the goal oriented based on the employee's job performance and job performance evaluation, analysis, and improve the behavior of employees work in enterprises, give full play to the potential and enthusiasm of the staff, to better achieve the goal of the procedures and methods. The traditional staff performance management methodology could be separated into the following parts. (1) Performance plan. Performance plan is of a certain enterprise employee performance expectations and get the 
recognition process. Performance plan must be clearly expect employees to achieve results and to achieve the results desired employee's behavior and skills, which determine the work target. The design of the work target is the goal of a bottom-up process is determined, through this process will be personal goals, departments, combining with enterprise goals. Target design is also a full participation in management, clarify the responsibilities of their employees and the process of the task is a key link in the process of performance management. Because employees only know the enterprise or department to oneself what is expected, they can be through their own efforts to achieve the desired results [3-4]. (2) The performance evaluation. Performance evaluation is a work according to the pre-determined target and its measure, check staff to complete the performance of the process. With enterprise special human capital of employees are likely to have the skills, is the enterprise has a unique early in an employee's career, more should be made for the examination. (3) Performance feedback. Performance evaluation can be continuous effectively, rewards and punishment is a critical factor in a timely manner. Needs is the starting point of the motivation and behavior process, everyone has this or that the needs of different levels of employees with the needs of different levels, such as money, status, a sense of achievement, some kind of desire only through the efforts to meet their own needs, will continue to pursue higher goals. Through the performance feedback, found that workers need to improve place, urge employees to learn, pay more attention to the improvement of future performance. (4) The performance of communication. Performance communication refers to the managers and employees work together, to share information about the process. This information includes the progress of the work, potential obstacles and problems, and possible measures to solve the problem and how managers can help employees and so on.
Managers at the time of performance appraisal management, pay attention to the reasonable breakdown the work objectives and the work content and responsibilities specific to each person of each department, so we are easy to put in place during the performance review. Moreover is the performance appraisal is no longer simply check references, check references must be combined with field trips instead of just look at the employee's data for how must also went to the field investigation of the employee's job performance to do a fair and reasonable decision.

The Performance Management Process Model. Enterprise human resources work mistakes tend to believe that performance management is performance appraisal or performance review, but essentially they are two completely different concepts. The emergence of the concept of performance management is performance evaluation work development to the inevitable requirement of modern industrial society. Modern scholars research is generally believed that the performance evaluation is an important part of the process of performance management, performance management is not a simple, not evaluation, performance evaluation is not intentionally seek staff error, not forcing employees to work, not work once a year, but through the joint efforts of and communication between the employees and managers to improve employee performance, and instructed barriers affect performance and eliminate or looking for a way of management process. Through the above research results of enterprise competitiveness theory of correlation analysis, we can see clearly that there are many factors of enterprise competitiveness internal source. We must first build competitiveness oriented performance management system based on the relevant requirements, puts forward a selection principles and standards. (1) Whether it could combine with staff, management staff and management as the can to the root causes. As a result of our performance management system is designed in view of the employees, therefore, 
cannot be combined with employees competitive source is not included in the enterprise employee performance management system. (2) Whether it could be combined with enterprise performance evaluation index. The competitiveness of our elected root factors must be combined with employee performance evaluation index system. In the next paragraph, we will illustrate the issues in detail.

Based on our competitive factors behind the selection principles and standards, we selected the following the internal cause of factors in a concrete analysis of enterprise's competitive power. (1) Staff team spirit and ability. Enterprise competitiveness has its certain external factors of enterprise's external environment factors is complex and changeable, have very important influence on enterprise competitiveness. The ability to respond to external environment of enterprises, on the enterprise competitiveness is very important to obtain and maintain. The enterprise response ability is refers to the enterprise external environment opportunities and threats of reaction rate and internal adjustment ability to adapt, it can make the enterprise to gain or maintain competitive advantage. (2) Employees the ability to learn. For any enterprise, employees the ability to learn is difficult to buy in the market, can only rely on their training and development. Especially the arrival of information age, the speed of knowledge update, everyone has to grow in learning, learning in the growth. (3) The enterprise culture. Corporate culture is to guide the enterprise management and employee behavior value system and the management idea, is the enterprise in the operation and management activities to create spiritual wealth. Corporate culture with strong initiative and stability, and has a deep influence on enterprise employee behavior, high efficiency of the enterprise resources, to improve performance with a strong supporting role, is the source of enterprise cohesion and competition. (4) Employees' innovation ability. The competitiveness of the enterprises to obtain superior to other enterprises and keep the lasting competitive advantage, must be within the enterprise each link, all aspects to be comprehensive innovation. For all enterprises, innovation is the source of enterprise competitiveness is beyond doubt. (5) Employee execution. When companies or basic determine strategic direction, the employee's ability to execute is particularly critical. The strong enterprise competition ability must be an employee execution strong enterprise, employees execution is a necessary condition for enterprise success, enterprise success without staff's execution, the enterprise staff performance management system should also be employees of performance indicators were focused on execution.

The Suggestions for the Enterprise. The traditional performance appraisal often ignores the performance management process. Performance appraisal and performance management are not equivalent. Performance management is to point to in order to achieve the goals of the organization. The formation of organizational goal expected profit and yield. , promote the teams and individuals to make the behavior of interests to achieve goals. The target management and performance goal setting is actually a head set goals together, achieve different levels of performance. When after completion of the employee's personal goals, the manager will compare the actual performance and the performance goal. For each employee's work performance evaluation: find out what the company's goal is complete, the enterprise target was not completed or what not to do. Seriously sum up experience and lessons in the process of management by objectives. Find out the real reason for enterprise didn't finish the goal, earnestly solve.

The theory of management by objectives, only achieve the goal of performance evaluation can be allowed to participate in the next round of goal setting and executing the next task and specific target management. Impossible because employees do not complete, give him more time 
to work. He still needs to involve the next round of setting goals. Gradually realize quantitative management is a kind of trend. If it can be a scientific and effective quantitative management inevitably can greatly improve the management efficiency and quality. Simply use the scientific evaluation system for each position responsibility for scientific evaluation, find out the most reasonable working conditions and the current state responsibility and efficiency. For this kind of quantitative management must carry out assessment methods and the inspection frequency.

\section{Conclusion}

In this paper, we conduct in-depth research on the new enterprise staff performance management methodology based on the management process model. Enterprise's overall operating performance is closely connected with corporate strategic planning and goal setting, but more specific performance for is closely related with the performance of individual employees. Employees can drive the improvement of organizational performance. Improve and eventually realize the whole change of enterprises. So research is an effective means of enterprise employee performance management is particularly important to the development of enterprises. Our research provides the modern enterprise with the novel methodology for performance management which will be meaningful.

\section{References}

[1] Lam S S K, Yeung J C K. Staff localization and environmental uncertainty on firm performance in China[J]. Asia Pacific Journal of Management, 2010, 27(4):677695.

[2] Gillmann M, Wei08enfels J, Weikum G, et al. Performance Assessment and Configuration of Enterprise-Wide Workflow Management Systems[J]. Enterprise, 1999, (1999).

[3] Guo X. Empirical Research on Innovation of Entrepreneurial Opportunities 、 Psychological Empowerment of Employees and Enterprise Performance[J]. Shanghai Management Science, 2011.

[4] Yuan Y H. On Performance of the Communist Party Members' Progressiveness in Enterprise Production and Management[J]. Journal of Jianghan Petroleum University of $\begin{array}{lll}\text { Staff } \quad \text { \& } \quad \text { Workers, } & 2007 .\end{array}$ 